\title{
EDUCAÇÃO PROFISSIONAL EM SAÚDE: REFLEXÕES SOBRE A AVALIAÇÃO
}

PROFESSIONAL HEALTH EDUCATION: REFLECTIONS ON ASSESSMENTS

Denise Antunes de Azambuja Zocche 1

Resumo O objeto de reflexão deste artigo é a avaliação por competência no ensino técnico em enfermagem, suas implicações, desafios e proposições como uma forma de integrar os diversos olhares dos atores envolvidos no processo de ensino-aprendizagem em saúde. A avaliação como caminho para a transformação e emancipação possíveis qualifica e dignifica o ensinar e o aprender. As palavras ditas na avaliação, quando servem para inspirar atos de cuidado, podem produzir autonomia para o aprendiz, revisão para os educadores, satisfação e segurança para os cuidadores, conforto e alegria para os usuários e qualidade para os serviços e o sistema de saúde.

Palavras-chave educação profissional; enfermagem; avaliação educacional; saúde e educação.
Abstract This article reflects on competency assessments in technical nursing education, their implications, challenges, and propositions as a way to integrate the views those involved have regarding the health teaching-learning process. Assessment as a path towards possible transformation and emancipation qualifies and dignifies teaching and learning. The words used in the assessment, when used to inspire acts of care, may give the apprentice autonomy, allow educators to undertake reviews, lead to satisfaction and security among caregivers, to comfort and happiness among users, and to quality for both health services and for the health system.

Keywords professional education; nursing; educational assessment; health \& education. 


\section{Introdução}

Ao longo dos anos de prática na saúde e no ensino técnico em saúde, venho revivendo, em cada situação da avaliação, muitos questionamentos, com relação ao processo da avaliação em si e aos sentidos da avaliação na produção de perfis profissionais. Vivi momentos de mudança no ensino técnico, por conta das reformas da educação profissional posteriores a última Lei de Diretrizes e Bases da Educação Nacional (LDB), que me levaram a rever, no interior de um processo institucional nacional, o meu próprio processo de trabalho. Com isso, se fez necessária, para mim, a discussão das questões relacionadas com o mundo do trabalho, com o trabalho em saúde e com a lógica do cuidado na prestação de atenção integral à saúde.

Pensar em avaliação, tomando este contexto, implicou ir além de um pensar a reformulação de planos de curso ou de aula, conselhos de classe ou propostas curriculares participativas, envolveu a discussão dos processos de orientação das escolhas sobre conteúdos, metodologias pedagógicas, cenários de práticas e, principalmente, sobre a avaliação das aprendizagens cognitivas e laborais de caminho e de tomada de decisões.

Embora tenha ocorrido um esforço de reforma da educação profissional e se tenha admitido que conhecimentos resultam de atuação, vivência e exposição pessoal, ainda há uma luta dentro de seu próprio conceito e interpretação, principalmente no que tange à competência profissional. Esta luta está evidenciada nos desenhos curriculares fragmentados e especializados, apesar dos discursos sobre práticas reflexivas e construção de autonomia; na ausência de reflexão pelas cargas horárias preenchidas de conteúdos e estágios; nos corpos docentes flutuantes, sem carreira, mal remunerados, sem qualificação para o ensino e sem acesso à pesquisa, além de uma rotatividade acrítica dos aprendizes pelos campos de prática.

No texto que se segue, reordeno as formulações que justificaram a apresentação de minha dissertação de mestrado em educação, intitulada Teias da avaliação no ensino-aprendizagem em saúde: uma análise de situação da avaliação dos desempenhos cognitivo e laboral no ensino técnico em enfermagem, defendida em agosto de 2006, na Universidade Federal do Rio Grande do Sul.

\section{Realidade da educação profissional e seus desafios contemporâneos na área da saúde}

As reformas educacionais ocorridas nos final dos anos 90, do século passado, foram realizadas sob a orientação e apoio financeiro de organismos 
internacionais; tinham por objetivo articular e subordinar a produção educacional às necessidades estabelecidas pelo mercado de trabalho e à necessidade de estabelecer mecanismos de controle e avaliação da qualidade dos serviços educacionais (Tanguy, 1997; Deluiz, 2001). Estas reformas geraram muitos debates e discussões, principalmente após a resolução da Câmara de Educação Básica, do Conselho Nacional de Educação, de $\mathrm{n}^{\circ} 4$, de 4 de dezembro de 1999, que instituiu as Diretrizes Curriculares Nacionais para a Educação Profissional de Nível Técnico, em que a formação passou a ser pautada pela noção de 'competências profissionais': uma definição de competências das profissões para as quais se vai educar/formar, um desenvolvimento de competências para a laboralidade e uma certificação profissional embasadas nas competências de cada área profissional e profissão.

A resolução $\mathrm{CEB} / \mathrm{CNE} \mathrm{n}^{\circ}$ 4/1999 trouxe como diretiva à educação profissional sua integração às diferentes formas de educação, ao trabalho, à ciência e à tecnologia, pensando critérios de cidadania e direito ao desenvolvimento permanente dos trabalhadores relativamente ao trabalho, mas também à vida social $\left(\operatorname{art} .1^{\circ}\right)$. Neste contexto, a competência profissional foi descrita como a capacidade de mobilizar, articular e colocar em ação valores, conhecimentos e habilidade necessários para o desempenho eficiente e eficaz das atividades requeridas pelo trabalho (art. $6^{\circ}$ ).

Deluiz (2001) diz que as novas formas de organização e gestão do trabalho, influenciadas pelo toyotismo ${ }^{2}$, exigiram dos trabalhadores um domínio do conhecimento científico-tecnológico e sócio-histórico que tornaram obrigatório o desenvolvimento do ensino, segundo uma pedagogia das competências. $\mathrm{O}$ mundo do trabalho seria constituído de atividades produtivas que podem ser identificadas em três grandes segmentos produtivos: de bens, de conhecimentos e de serviços. Nessas atividades produtivas se assentam as Diretrizes Curriculares Nacionais para a Educação Profissional de Nível Técnico. Cada um desses segmentos tem processos próprios, ou seja, demanda funções específicas que realizam operações segundo determinadas normas, métodos e técnicas. A área da saúde está enquadrada como produção de serviços.

Dentro do segmento da produção de serviços, a educação profissional em saúde está pautada em princípios específicos, coerentes com a implementação de uma nova estrutura de ensino técnico: as competências profissionais em saúde. Quando da elaboração das Diretrizes Curriculares Nacionais para a Educação Profissional de Nível Técnico (art. 7o, do decreto federal no 2.208/97), ficou estabelecido que deveriam ser realizados estudos de identificação do perfil de competências profissionais, ouvindo-se os setores interessados, incluindo trabalhadores e empregadores. Portanto, a definição de competências e habilidades e das bases tecnológicas requeridas para a formação de um profissional de saúde deveriam estar embasadas em 
uma análise do processo produtivo da área profissional, levando-se em conta critérios de flexibilidade e laborabilidade.

A proposta apresentada pelo Ministério da Educação falava de um currículo voltado para o desenvolvimento de competências, no qual a flexibilidade, interdisciplinaridade e contextualização ${ }^{3}$ permeassem a prática peda-gógica: educar para a vida e preparar para o mundo do trabalho. Podemos perguntar, entretanto, que mundo é esse onde se insere o trabalho e quem são os seus atores? Que vida é essa e como nela se produzem o socius e a subjetividade?

Comparando a experiência internacional na implementação de sistemas de certificação profissional embasados em competências, Deluiz (2001) aponta que há dificuldade para a identificação das competências e falta agilidade técnico-administrativa para a incorporação da complexidade técnica aos currículos. As dificuldades dizem respeito aos referenciais para definir competência profissional, bem como à insuficiência de instrumentos para captar a dinâmica do mundo do trabalho. Na educação profissional, a autora chama atenção para o fato de que o modelo das competências invade o mundo da educação, diante das exigências de competitividade e produtividade e que, mesmo tendo um conteúdo subjetivo e individual, elas são construídas ao longo da vida profissional.

Não podemos esquecer que o trabalho tem seu papel no desenvolvimento humano e que ele define de maneira importante as oportunidades de vida. Considerando as idéias de Deluiz, fica um alerta para os profissionais da saúde e da educação quanto à possibilidade de a noção de competência servir como uma armadilha ou um disfarce para, no fundo, restaurar o velho tecnicismo, centrando o ensino técnico no fazer, além de subordinar a reflexão ao andar das operações do trabalho e não à sua crítica e problematização. Segundo Ramos (2001), as reformas educacionais que ocorreram em diversos países evidenciaram a busca de formalização de uma pedagogia embasada em competências caracterizada pela flexibilização e pela valorização da subjetividade, contrapondo à qualificação formal os conhecimentos tácitos.

A idéia difundida, quanto ao uso da noção de competências pela escola, é que ela deve promover o encontro entre trabalho e formação, enquanto, do ponto de vista empresarial, competência se confunde com qualificação aplicada às necessidades do processo produtivo. Essa abordagem tem duas dimensões bem definidas, uma relativa ao trabalho, outra à prática pe-dagógica. No contexto pedagógico, quando o ensino por competências co-meçou a ser aplicado no Brasil, tendo por base as políticas educacionais, em que o conceito de competência assume um papel importante nas Diretrizes Curriculares Nacionais para o Ensino Médio, para a educação profissional e para a formação de professores, surgiram muitas dúvidas entre os profissionais da educação. 
Um dos limites a ser considerado no ensino por competências é a tendência à supervalorização dos saberes profissionais operativos, evidenciandose uma separação entre a concepção e a execução do trabalho, ficando claro, então, que, ao confundir habilidade com competência, voltamos à abordagem tecnicista da educação profissional, aquela que conduz a uma forma individualizada e repetitiva de trabalho, sem reflexão e sem construção social. O trabalho, entretanto, deveria ser algo construído nas relações sociais, com outros membros da equipe, com os consumidores do trabalho e dentro da cadeia produtiva onde o trabalho gera bens, serviços e conhecimentos.

Ao resgatar o conceito de competência no contexto do trabalho, Kuenzer (2003) retoma a origem da certificação por competências, lembrando que esta surgiu nos anos 70, do século passado, determinada por uma modalidade peculiar de divisão social e técnica do trabalho, fundamentada na parcelização, assumindo, assim, o significado de um saber-fazer, derivado da experiência.

Embora muitos autores defendam a integração entre conhecimentos formais e conhecimentos tácitos, Kuenzer afirma que há dificuldade na utilização de conhecimentos prévios dos aprendizes, pois as desigualdades socioeconômicas dificultam o acesso à produção cultural dominante. A escola, nesse caso, é espaço fundamental para permitir o desenvolvimento das competências requeridas para a inclusão social e na vida produtiva.

Perrenoud (1997, p. 7) define competência como "uma capacidade de agir eficazmente em um determinado tipo de situação, apoiada em conhecimentos, mas sem limitar-se a eles". Para esse autor, competência seria a capcidade de articular um conjunto de esquemas embasados em conhecimentos, a fim de mobilizá-los 'em situação', no momento certo e com discernimento para enfrentar uma realidade da melhor maneira possível, agindo em sinergia vários recursos cognitivos complementares. Os conhecimentos são recursos cognitivos importantes, mas não são suficientes para operar ações na realidade, tendo de ser construídos na relação com o outro (Perrenoud, 1999).

Ao pensar nas várias teias em que se insere uma competência, Perrenoud (2001) abandona sua significação terminológica para destacar sua construção nas relações em que um sistema de ensino está implicado. $\mathrm{O}$ autor enfatiza a importância de mobilizar um conjunto diversificado de conhecimentos da profissão, esquemas de ação e posturas que são requeridas no exercício profissional.

Quando analisamos as mudanças ocorridas na educação profissional e pensamos criticamente sobre a formação embasada em competências, alguns pontos, como o do processo de aprendizagem, são marcantes. Segundo Ramos (2001), este ocupa um lugar central na pedagogia embasada nas competências, em que o aluno é valorizado como o foco da aprendizagem e a 
construção do conhecimento deve ser significativa. Assim, se propõe pensar o ensino de forma a oferecer espaços e situações de aprendizagem que possam contribuir para o desenvolvimento de competências laborais.

Trazer esta discussão para o campo da saúde torna-a um desafio bastante mais complexo que aplicá-la sobre o setor produtivo industrial, comercial ou informacional. A saúde compreende uma variedade de atividades de produção e de serviços distribuídos em diferentes âmbitos: hospitalares, ambulatoriais e laboratoriais, passando pela produção de tecnologias, conhecimentos e informação. O foco das atividades de saúde são as pessoas e coletividades, portanto, o processo de trabalho é pautado no contato humano e na relação entre esses.

Com relação à noção de competência expressa nas Diretrizes Curriculares Nacionais para a Educação Profissional de Nível Técnico, Deluiz (2001) considera que há uma visão construtivista, que compreende as competências como as ações e operações que articulam conhecimentos (o saber), habilidades (o fazer), valores (o ser) e atitudes (o conviver), constituídos de forma articulada e mobilizados em realizações profissionais de qualidade. Segundo a autora, as diretrizes, mesmo estando pautadas numa concepção construtivista, operacionalmente se apóiam numa perspectiva funcionalista, ao interpretar as competências como um rol de atribuições técnicas transponíveis aos perfis que descrevem as funções e qualidades requeridas pelo trabalho.

O contexto pedagógico parece ser esquecido, pois a abordagem que tem sido feita sobre a pedagogia embasada nas competências revela-a como um meio para adequar o trabalhador segundo sua melhor adaptação aos novos processos de produção. Conforme Barbosa, Gontijo e Santos (2004), atualmente o modelo de educação profissional tem por objetivo adequar a educação às novas demandas sociais, propondo, para a organização dos cursos, a contextualização dos conteúdos, a flexibilização curricular e a interdisciplinaridade dos programas, possibilitando aos planos serem regidos por disciplinas, etapas ou módulos, atividades nucleadoras e projetos.

Este modelo representa um novo paradigma de ensino, que tem como desafio metodologias ativas para desenvolver no aprendiz a capacidade de 'aprender a aprender'. No contexto da educação profissional por competências, destacam-se métodos de ensino em que a contextualização do que deve ser ensinado esteja presente. Esta contextualização se faz por meio de projetos; prática profissional em laboratórios e oficinas; realização de pesquisas como instrumento de aprendizagem; utilização das tecnologias da informação; realização de visitas técnicas; realização de estudos de caso; promoção de trabalho em equipe.

As escolas de formação profissional em saúde, mais precisamente as escolas técnicas em enfermagem, têm ajudado a perpetuar a idéia de que a 
inserção profissional e a qualificação para o trabalho são atributos individuais, como se o trabalho não fosse historicamente determinado e não estivesse relacionado com múltiplos contextos produtivos, com a crescente renovação de sistemas tecnológicos, com a alta especialização e com a constante introdução de procedimentos dependentes de equipamentos de apoio diagnóstico e terapêutico.

Mesmo sendo uma profissão que lida com fenômenos complexos, como os de vida e de morte, sentimentos e emoções, sofrimentos e aflições, a enfermagem é muito submetida ao modelo tecnicista, pois a maioria das instituições de saúde trabalha de forma fragmentada, embasando-se em normas técnicas rígidas e estruturando-se de maneira hierarquizada. Esta organização do trabalho centrado no fazer segue o modelo da divisão de tarefas, sem apropriação coletiva do processo de trabalho, ficando muitas vezes a interação pessoal em segundo plano ou fora das análises sobre formação e desempenho profissional.

Nas práticas supervisionadas da educação profissional (campo de estágio), ainda perpassam as idéias de que o ensino técnico é sinônimo de treinamento, realizado por trabalhadores que precisam saber fazer, mas não precisam deter o saber sobre por que ou para que as práticas se fazem, desde que aprendam o fazer de cada procedimento, quando, na realidade, deveriam estar em desenvolvimento oportunidades de experimentação e crescimento pessoal.

As relações de aprendizado se dão pelas experiências vividas pelos aprendizes dentro das organizações de saúde que, como disse Campos (1997), são todas recortadas em departamentos, divisões e seções, montadas segundo as profissões, corpo clínico de médicos, unidade de enfermagem, serviço de assistência social, área de nutrição etc., nas quais os trabalhadores são como instrumentos, coisas ou recursos destituídos de vontade ou de projeto próprio. Deste modo, as atividades se transformam em atos mecânicos e monótonos, o que explica, em grande parte, a rotina de trabalho e a queda de qualidade da assistência prestada: aquele profissional que não olha nos olhos, que não se emociona mais diante de um óbito ou de um nascimento, que foi aos poucos perdendo a sensibilidade ou aprendeu muito bem a embotá-la. Dessensibilização gerada pela incapacidade de compreender e identificar a importância de seu fazer na equipe de saúde. O coletador que colhe material biológico para exame, o médico que prescreve, o pessoal de enfermagem que presta cuidados, todos aprenderam a operar mecanicamente. Mesmo querendo fornecer o máximo de informações, ao ensinar um tema é preciso que se discuta sobre o que é, onde fica, qual é a cor, onde começa e como termina. Mas se é vivenciando, sentindo, operando a construção do conhecimento que aprendemos, avaliar também deveria passar por esta lógica. Como diz Hoffman (2005), pensar no aluno, em como vive, em como 
aprende e de que jeito aprende, entre outras questões, é ponto crucial para avaliar melhor. O que não se avalia, não se qualifica como relevante aprendizado.

Nem sempre é no tempo de formação escolar que alcançamos uma aprendizagem, mas, por exemplo, se quisermos ensinar como identificar os sinais de um trabalho de parto, entre eles, o que é uma contração, o porquê e quando começa, qual sua intensidade e a sua duração, toda a informação perde sentido se não oportunizarmos a observação ou o contato com a mulher durante a contração, seu comportamento, atitudes e sentimentos. Se avaliarmos a habilidade em um procedimento prestado no 'laboratório', nada nos assegura que ele seja transponível para a situação em ato.

Utilizar a pedagogia embasada nas competências no ensino técnico em enfermagem não significa usá-la como uma lista abstrata ou como um checklist, como se estivesse relacionada apenas às habilidades técnicas mensuráveis e quantificáveis. Há o risco, na substituição das competências pelas habilidades, de não darmos conta de um mínimo de diversidade necessária ao desenvolvimento do pensamento crítico e de práticas sensíveis. A aprendizagem real do cuidado se dá no ato de cuidar e de ser cuidado, é sendo solicitado a cuidar, é sendo 'tocado' (afetado, sensibilizado) pelo conhecimento que aprendemos. Ayres (2004) chama atenção sobre a responsabilidade de cada profissional ou equipe de saúde, gestor ou formulador de políticas, em relação aos projetos de felicidade daqueles que cuidam, o trabalho em saúde é e precisa ser comprometido com aqueles por quem se justifica existir.

Para oportunizar este encontro do cuidador com aquele que é cuidado, Pereira (1995) chama a atenção para estratégias e experiências mais dinâmicas. Dentre estas estratégias, destaca a manutenção do diálogo que favoreça a troca de experiências e a compreensão dos seus significados para cada estudante, um diálogo quanto à experiência vivida por professores, estudantes, enfermeiros e usuários. O ensinar transforma-se em aprender, no esforço de entender, e o aprender em ouvir, no sentido do entrar em contato.

Waldow (1998) salienta que o processo de cuidar realizado com um usuário (o 'ser' cuidado), no sentido de promover, manter ou recuperar a dignidade e a totalidade humana, engloba também um processo de transformação do cuidador e daquele que é cuidado. Somente vivendo a experiência do conhecimento, sentimos o que é cuidar.

Nos relatos de Izabel dos Santos, uma das ilustres figuras da história da formulação de políticas de formação para o ensino técnico em enfermagem na região das Américas, sobre o processo de aprendizado em sua prática profissional, encontramos a reiterada afirmação de que "quando você aprende uma coisa fazendo, você modifica a sua prática automaticamente". Para ela, quando alguém aprende, não consegue mais fazer sem um jeito preciso e pessoal aquilo que aprendeu, "isto é, se você aprende mesmo, se 
você processa o novo dentro de você, você se modifica enquanto pessoa" (Castro, Santana e Passos, 2002, p. 53).

Por mais que um educador ilustre ou relate, ele nunca chegará perto da experimentação que reconstrói, relembra e recria um cuidar próprio e com significados pessoais, mas precisa, ainda, inventar o 'seu' cuidar. Esse sentido e ato pedagógico precisam de inclusão na avaliação. Os enfrentamentos oportunizados por situações-problema e estudos de caso são um campo rico, permanentemente alimentado pela capacidade dos aprendizes de aprender. No ato de cuidar e de aprender cuidando, vários sentimentos e desafios são mobilizados nos aprendizes, como pessoas e como profissionais. No contexto da avaliação em educação profissional, a aprendizagem tem estado centrada nos resultados individuais do desenvolvimento de habilidades específicas e de atitudes. Esta inquietação exige a formulação de atos participativos e a construção de espaços permanentes para a revisão das práticas de formação e avaliação.

\section{Avaliação por competência/certificação profissional: validação dos desempenhos cognitivo e laboral}

Trabalhar com ensino técnico em enfermagem exige um exercício de pensar e fazer saúde de forma intensa, pois este profissional é aquele que fica mais perto de quem é cuidado, é aquele que ouve mais, que toca mais, que acolhe as falas espontâneas e presta os procedimentos que afirmam a cada rotina que a pessoa está numa instituição de saúde (injeções, curativos, verificação dos sinais vitais, observação do gotejo do soro, condições de conforto etc.). Falo de intensidade, pois ensinar alguém a cuidar de outro mobiliza emoções e sentimentos entre todos os envolvidos neste processo: contato com sangue, humores corporais e secreções; convívio com seqüelas; interação com os estados de aflição e de retorno à integridade física e/ou mental. $\mathrm{Na}$ enfermagem, aprendemos uns com os outros e uns nos outros, o que mobiliza várias potencialidades, sentimentos, medos e desejos.

As questões sociais e culturais são muito importantes na construção do conhecimento e na avaliação, pois a prática do cuidado requer essa apropriação tanto quanto do aparato técnico que aumenta a cada dia e que, entretanto, não garante, por si mesmo ou por seu uso com destreza, saúde nem qualidade de vida.

Ao conviver com estudantes do ensino técnico, aprendi muito, pois com seus saberes, com sua forma de olhar o mundo de forma descomplicada, entendi que trabalhar com as pessoas é muito mais relevante do que 'treinálas' para determinado procedimento ou para o fazer específico de uma técnica de cuidados. Percebo que determinadas pessoas sentem-se bem, 
melhoram ou permanecem mais estáveis ao serem atendidas por determinados cuidadores que nem sempre possuem um domínio das habilidades técnicas, mas acolhem e escutam de forma diferenciada.

Venho ao longo da minha prática docente convivendo com vários processos de avaliação, não somente os de desempenho cognitivo, aqueles da sala de aula ou dos conselhos de classe, mas também os de desempenho laboral, aqueles no campo de trabalho ou das passagens de plantão nas unidades de enfermagem. Dentro deste segundo processo, um tipo particular de avaliação vem ocupando minhas reflexões, a que é feita nos períodos probatórios admissionais ao emprego em enfermagem. Esta constitui também uma forma de avaliar na formação técnica, é o momento em que as habilidades e competências são postas à prova pelos serviços de saúde. Muito mais por adequação ao perfil da instituição do que pelas capacidades profissionais adquiridas ao longo da formação ou do trabalho. Percebo que os docentes e os enfermeiros avaliam mais o fazer hábil (conforme um padrão) e rápido e, além dos instrumentos formais quantitativos ou qualitativos como os de uma prova, teste ou exame, o que efetivamente tem peso é o comportamento no campo prático. Também percebo que, por vezes, não avaliam, mas julgam e emitem veredictos, como se o cuidar ou o ensinar fossem trabalhos dotados de verdades e certezas, capazes de separar certo e errado e bom e mau de maneira taxativa. Mesmo sabendo que normas, rotinas e protocolos são distintos em cada instituição, em cada tempo histórico e em cada lugar, os comportamentos docentes são de supervisão para a regulação heterônoma das condutas profissionais. Onde está o papel da escola na atualização pedagógica dos educadores que participam desta formação e dos serviços de saúde na educação permanente de seus trabalhadores?

Se os funcionários se tornam lentos, sem iniciativa, frios, distantes e com dificuldades de relacionamento, não é pura e simplesmente por uma questão de personalidade ou de caráter ou de fundamentação teórica, mas uma questão relativa ao ambiente de trabalho onde atuam e interagem e à qualidade das relações nesses locais, que contribuem em muito para o desenvolvimento das habilidades no trabalho e padrões ao ser trabalhador.

Ao conviver com atendentes e auxiliares em formação para serem técnicos de enfermagem, testemunhei o despertar e o amadurecer para o cuidado em enfermagem de forma mais participativa e menos tarefeira, mediante reflexões críticas sobre o fazer, incluindo a valorização das suas falas e das associações entre a prática de anos e as informações, digamos, 'novas', tratadas nos textos didáticos trazidos à sala de aula ou nos manuais de técnicas fundamentais estudados durante a formação. Seus relatos e associações são muito ricos de detalhes e de idéias para a promoção da saúde dos usuários de suas instituições hospitalares, ambulatoriais, farmacêuticas ou nos domicílios. 
Avaliar todo este processo de mudança vem sendo um desafio por vários motivos. Na realidade, muitos aprendizes já dominam conhecimentos e práticas além das habilidades propostas para um técnico em enfermagem, mas não possuem a certificação nem o reconhecimento legal, o que lhes causa desânimo, pois ao passar por experiências teórico-práticas mais ensinam do que aprendem. Queixam-se de que não aprendem muita coisa nova ou técnicas novas. Isto se reflete no processo de aprendizado por meio do pouco envolvimento com o curso ou por meio das suas faltas, embora, demonstrem, por força do percurso pelo curso, um potencial maior e mais segurança no fazer.

O desenvolvimento da iniciativa e da autonomia no desempenho do cuidado e, conseqüentemente, nas relações de trabalho hospitalar gera inquietações e até mesmo um certo mal-estar entre os enfermeiros e na administração hospitalar, pois funcionários mais reflexivos muitas vezes não são bem aceitos, numa relação de trabalho hierarquizada como a da enfermagem. Ao serem avaliados de forma positiva, têm seu fazer confirmado e reconhecido, tornando-se, tanto no âmbito pessoal como diante da família e da sociedade, mais confiantes e ativos em formulações e proposições. Suas atitudes ficam mais afirmativas e sua subordinação mais discutível.

A experiência da minha prática docente me fez repensar o meu fazer como enfermeira e como educadora. Saber avaliar todas estas nuances e considerá-las como parte do processo de qualificação e de aprendizado foi importante para o meu crescimento pessoal e profissional. Foi, então, que optei por trabalhar mais a partir dos aprendizes, de seus saberes e de suas histórias de vida (por mais tecnicista que fosse o conteúdo a ser trabalhado) e a oferecer situações, na prática do cuidado, que me permitissem perceber nos olhos dos aprendizes o que pode ser uma boa situação de aprendizado, escutando mais, observando, me deixando acompanhar e observar, muito mais que falar, treinar e repetir.

É muito comum nos cursos técnicos um aprendizado orientado pela fragmentação das pessoas sob cuidado, para áreas determinadas e segundo as necessidades do mercado privado do trabalho ou das instituições privadas, e não pelas necessidades locais de saúde, individuais e coletivas e de promoção da saúde, como preconiza o sistema de saúde no Brasil. Ainda quando se fala em de ensino técnico em enfermagem, associa-se esta categoria profissional ao trabalho em 'áreas fechadas', de cuidados mais intensivos e dependentes de equipamentos e rotinas, um trabalho de expres-são/execução de técnicas.

Criar um currículo que atenda aos interesses profissionais é desgastante e, ao mesmo tempo, um aprendizado, pois trabalhar com competências ainda é uma proposta muitas vezes 'do papel'. Ainda acontece certa confusão, é comum a escola acabar transpondo objetivos gerais e específicos em habi- 
lidades e competências ou conjugar com verbos as regras do trabalho de modo que indique ação de aprendizagem.

Ensinar por competências, entretanto, tem de ser um ensinar de modo abrangente, sair do ensino por 'transmissão' e ousar uma educação de uma forma mais integradora e reflexiva, no sentido de desenvolver nos aprendizes habilidades para saber viver e não somente para saber fazer. Tendo vivido estas experiências com o tema avaliação, primeiro como aprendiz, posteriormente como educadora e, também, como cuidadora em instituições de saúde, experienciando sistemas de avaliação por notas e por conceitos, senti a inquietação de avaliar por competências.

As Diretrizes Curriculares Nacionais para a Educação Profissional de Nível Técnico colocaram em questão como estão sendo acompanhadas e vividas, na educação profissional, as práticas de avaliação. A avaliação por competências consiste em avaliar - em situações concretas - as competências adquiridas durante um processo formal de ensino e no ambiente de trabalho. Dessas formulações, se chega a outro instrumento integrante da educação profissional: a certificação profissional, ponto máximo da avaliação.

A certificação implica um movimento de certificar que um aprendiz ou trabalhador adquiriu os conhecimentos, habilidades, valores e atitudes suficientes e adequados para o exercício de uma profissão regulamentada, cujos atributos foram consensuados por sua comunidade profissional. Requer, necessariamente, um julgamento, o que implica avaliação de saberes profissionais para o exercício profissional. É necessário, entretanto, dar uma maior atenção e focalizar que processos estão envolvidos na avaliação do desempenho cognitivo e do desempenho laboral no ensino técnico por competência e na certificação profissional, como também um processo do ensino-aprendizagem.

A certificação profissional configura o reconhecimento formal dos conhecimentos, habilidades, valores e atitudes do aprendiz ou do trabalhador, independentemente da forma como foram adquiridos, por isso, permite a flexibilidade nos modos do ensino, da avaliação e da incorporação aos postos de trabalho. Entretanto, é justamente por isso que deve ser pactuada como objeto da cidadania, capaz de respeitar os direitos sociais, trabalhistas e individuais e de promover o cumprimento dos deveres do Estado e da sociedade para com os trabalhadores.

É imprescindível uma política de avaliação que revele seu papel e sua função na educação profissional e os desafios apresentados aos atores envolvidos. Com relação à pedagogia embasada nas competências, estamos vivendo um processo de transformação que implica escolhas e mudança de paradigma, bem como desafiar a formação que estava construída por objetivos bem definidos e por práticas de treinamento e memorização para novas práticas de qualificação e avaliação. Segundo Saraiva e Masson (2003), a qualificação e avaliação necessárias estão em acordo com os princípios que 
reconhecem as experiências dos aprendizes no contexto do trabalho, o que obriga à mudança nos métodos de avaliar, reconhecendo não só o desempenho final em notas, conceitos ou escalas, mas também a trajetória percorrida e a experimentação subjetiva.

\section{Considerações finais}

Sabemos que há todo um apelo pelo avanço tecnológico, para os trabalhadores se adequarem cada vez mais às necessidades do mercado de trabalho, mas a formação não acompanha esses movimentos, nem de maneira autoral nem de maneira crítica e participativa. Os educadores acabam reféns dos modos de avaliar demandados nesse contexto. Avaliar o próprio contexto e avaliar as transformações necessárias, tanto na sala de aula como nos campos das práticas laborais, pode ser anúncio ou prenúncio de novo compromisso com as competências dos aprendizes para o trabalho em saúde. A utilização da avaliação por competências não pode servir à ordenação de atos de cuidado separados por fronteira, precisa constituir-se num espaço de reflexão, de rearranjo e de trocas, porque senão corremos o risco de 'conformar' cada vez mais o aprendiz e anular o potencial criativo do ser profissional da saúde. Por que a ênfase nas técnicas e sua execução, se o ensino por competências requer outros saberes? Se a avaliação dá maior importância às habilidades e destrezas (fazer), o processo de aprendizado fica comprometido, pois não se pensando nos usuários e sim nos procedimentos, reduzem-se e fragmentam-se a formação e a oportunidade que o encontro da avaliação oportuniza.

Acredito que a avaliação cognitiva e laboral no ensino técnico em enfermagem precisa ser ressignificada. Avaliar faz parte do processo de aprendizado, não é uma etapa final; avaliar é um momento de aprender a aprender porque envolve produção de sentidos, sentimentos, afetos e reflexões; requer compromisso de participação ativa no enfrentamento dos problemas de saúde e na construção de uma vida mais parceira. Por isso, a avaliação pode assumir o sentido de reinventar os saberes e as competências, de oferecer suporte para os atores envolvidos pensarem sua própria história, construindo e reconstruindo realidade a partir dos vários olhares sobre o ato de cuidar.

Tornar a avaliação uma atividade comprometida com o ensino e como recurso de aprendizagem lhe dá um significado estruturante na formação do aprendiz, mas para isto precisamos falar mais sobre avaliação, sobre como e por que avaliar. Penso que a avaliação integrará tudo o que se pensa sobre o cuidado humano se os diversos olhares dos atores envolvidos se cruzarem e se as falas e sensações ganharem corpo e ecoarem pelos espaços de ensino, 
não ficando presas numa folha de registro que só existe entre duas pessoas (aprendiz e educador). A avaliação deve ganhar vida no processo formativo da educação profissional. A avaliação como caminho para a transformação e para a emancipação possíveis qualifica e dignifica o ensinar e o aprender. Os produtos de avaliação, quando servem para inspirar atos de cuidado, podem produzir autonomia para o aprendiz, revisão para os educadores, satisfação e segurança para os cuidadores, conforto e alegria para os usuários e qualidade para os serviços e o sistema de saúde.

\section{Notas}

1 Pesquisadora da Universidade Federal do Rio Grande do Sul (UFRGS). Professora do Curso de Enfermagem do Centro Universitário Metodista - IPA, Porto Alegre, Brasil. Mestre em Educação pela Faculdade de Educação da UFRGS. <denise.azambuja@metodistadosul.edu.br>

$2 \mathrm{O}$ toyotismo se caracteriza por uma produção vinculada à demanda para atender às novas necessidades produtivas, tecnológicas e mercadológicas. Utiliza as idéias de cooperação, consenso, integração e participação, exigindo dos trabalhadores maior qualificação, multifuncionalidade e polivalência.

3 A 'flexibilidade' prevê a integração entre as diversas áreas do conhecimento, dentro do currículo ou entre cursos, ficando aberta a outros itinerários que não só os do próprio curso; a 'interdisciplinaridade' depende, basicamente, de uma mudança de atitude perante o problema do conhecimento, da substituição de uma concepção fragmentária pela unitária do ser humano. Práticas de ensino 'contextualizadas' partem do saber dos alunos para desenvolver competências que venham a ampliar este saber inicial, situando os alunos num campo mais amplo de conhecimentos, de modo que possam efetivamente se integrar na sociedade atuando, interagindo e interferindo sobre ela (Deluiz, 2001).

\section{Referências}

AYRES, José Ricardo Mesquita de Carvalho. O cuidado, os modos de ser (do) humano e as práticas de saúde. Saúde e Sociedade, São Paulo, v. 13, n. 3, 2004, p. 16-29.

BARBOSA, Eduardo Fernandes; GONTIJO, Alberto Figueiredo; SANTOS, Fernanda Fátima dos. Inovações pedagógicas em educação profissional: uma experiência de utilização do método de projetos na formação de competências. Boletim Técnico do Senac, Rio de Janeiro, v. 30, n. 2, p. 48-60, maio/ago. 2004.

CAMPOS, Gastão Wagner. Subjetividade e administração de pessoal: considerações sobre modos de gerenciar o trabalho em equipes de saúde. In: MERHY, Emerson Elias, ONOCKO, Rosana (Orgs.). Agir em saúde: um desafio para o público. São Paulo: Hucitec, 1997. p. 229-266. 
CASTRO, Janete Lima de; SANTANA, José Paranaguá de; NOGUEIRA, Roberto Passos. Izabel dos Santos: a arte e a paixão de aprender fazendo. Natal: UFRN, 2002.

DELUIZ, Neise. O modelo das competências profissionais no mundo do trabalho e na educação: implicações para o currículo. Boletim Técnico do Senac, Rio de Janeiro, v. 27, n. 3, set./dez. 2001. Disponível em: $<$ www.senac.br/boletim $>$. Acesso em: 20 jun. 2005.

HOFFMANN, Jussara. O jogo do contrário em avaliação. Porto Alegre: Mediação, 2005.

KUENZER, Acácia Zeneida. Competência como práxis: os dilemas da relação entre teoria e prática na educação dos trabalhadores. Boletim Técnico do Senac, Rio de Janeiro, v. 29, n. 1, jan./abr. 2003. Disponível em: <www.senac.br/boletim>. Acesso em: 21 maio 2006.

PEREIRA, Rosane Carrion Jacinto; GALPERIN, Mara Regina de Oliveira. Refletindo e escrevendo sobre as experiências vivenciadas no contexto da escola e do cuidado. In: WALDOW, Vera Regina; LOPES, Marta Júlia e MEYER, Dagmar Estermann (Orgs.). Maneiras de cuidar, maneiras de ensinar: a enfermagem entre a escola e a prática profissional. Porto Alegre: Artes Médicas, 1995, p. 135-149. PERRENOUD, Philippe. Avaliação: da excelência à regulação das aprendizagens entre duas lógicas. Porto Alegre: Artmed, 1999.
Ensinar: agir na urgência, decidir na incerteza. Porto Alegre: Artmed, 2001.

Construindo as competências da escola. São Paulo: Artmed, 1997.

RAMOS, Marise Nogueira. Qualificação, competências e certificação: visão educacional. Formação, Brasília, v. 2, n. 1, p. 17-26, 2001.

A pedagogia das competências: autonomia ou adaptação? 2. ed. São Paulo: Cortez, 2002.

SARAIVA, Suzana Barros Corrêa; MASSON, Máximo Augusto Campos. Competências, qualificação e avaliação: observações sobre práticas pedagógicas e educação profissional. Boletim Técnico do Senac, Rio de Janeiro, v. 29, n. 2, p. 43-48, maio/ago. 2003.

TANGUY, Lucie. Competência e integração social na empresa. In: ROPÉ, Françoise, TANGUY, Lucie (Orgs.). Saberes e competências: o uso de tais noções na escola e na empresa. São Paulo: Papirus, 1997. p. 167-200.

WALDOW, Vera Regina. Cuidado humano: o resgate necessário. Porto Alegre: SagraLuzzato, 1998.

Recebido em 16/04/2007

Aprovado em 06/07/2007 